\title{
The Surface Fine Structure Contact Deformation Mechanics and Experimental Verification
}

\author{
Xingchen $\mathrm{Li}^{1, \mathrm{a}}$, Qiang Zhang ${ }^{1, \mathrm{~b}}$ and Yiyong Huang ${ }^{1, \mathrm{c}}$ \\ ${ }^{1}$ National University of Defense Technology, Changsha 410073, China; \\ alixingchen_hit@163.com, bzhqi9290@sina.com, cyiyong_h@sina.com
}

Keywords: seal contact, fine structure, leakage.

\begin{abstract}
In order to realize the high efficient seal performance, according to the model that is completely deformed to contact substrate everywhere between hard substrate and soft substrate in Presson contact mechanics, the complete contact condition is advanced. Two gaskets with micrometer size surface fine structure were designed and fabricated in different manufacturing processes, which were aimed at verifying the correctness of the complete contact condition through the seal experiment. The seal performance of gaskets was investigated experimentally using the helium mass spectrum. In the light of experiment result, the leakage reason was that the soft substrate was not completely in contact with the surface of hard substrate. Verification by using different soft substrate was carried out, and the conclusion was that the complete contact condition was fit for the result. In the end, the result shows that fabricating the micrometer size structure on the surface of the hard substrate can efficiently improve the seal performance between the soft and hard substrate contact.
\end{abstract}

\section{Introduction}

During the long arduous exploration of outerspace, it is not a rare case that aerospace accidents occur due to the accidental leakage of seal structure. For instance, the world-shaking accident of the HMS Challenger is one of the cases, which was exploded 73 seconds after launch. And the tragical accident was caused by the failure of an O-ring gasket in the low temperature environment. Thus the performance of the seal structure is a key point to the normal operation of the spacecraft.

The existing seal structure, with less attention to the surface fine wave, is made by using rubber and smooth metal for contact. The following will show the model that was completely deformed to contact substrate everywhere between hard substrate and soft substrate in Presson contract mechanics, and two gaskets with the fine structure will verify the correctness of the complete contact condition through the seal experiment.

\section{The Contact Theory between Hard and Soft Substrate}

In the paper theory of rubber friction and mechanics [1],Persson put forward the contact model that the soft substrate like rubber made contact with the rough surface of the hard substrate. In that model, the sealing of the end surface is regarded as the contact between the soft substrate and the hard substrate; the soft substrate is considered as the very smooth surface elastomer and the hard as the rough rigid body, and the surface topography of the hard substrate is the overlay result of the actual contact surface. When the contact surface is simplified as a periodic corrugation with wavelength , and amplitude, the contact schematic diagram is shown in Fig 1. 


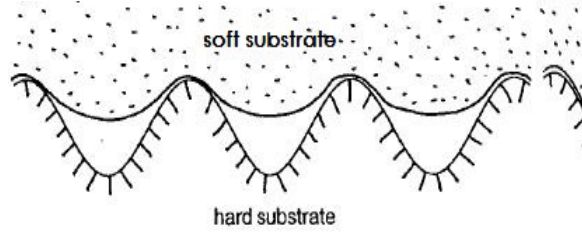

(a)

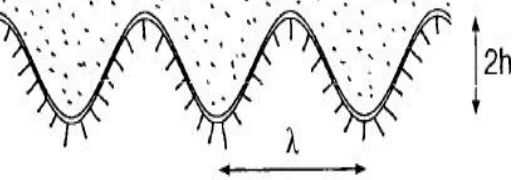

(b)

Fig. 1 The soft substrate squeezed against the hard substrate with a cosines corrugation. In (a) the deformation of the soft substrate is not in complete contact with the hard surface, while in (b) the deformation seals the corrugation completely.

If $A_{0}$ is the nominal contact area, i.e. the bottom area of the entire soft substrate, and $F_{N}$ is the load, then the average perpendicular stress is defined as $\sigma_{0}=F_{N} / A_{0}$. Firstly, assume that a uniform stress $\sigma$ performs within a circular area with the radius $R$ and centered at a point $P$. At the point $P$, the perpendicular displacement $u$ is easy to calculate using the continuum mechanics:

$$
u / R \approx \sigma / E
$$

And the result can be derived from simple dimensional arguments. As the displacement field is linearly related to the stress field (given that the linear elasticity theory is valid), the stress $\sigma$ has the same dimension only with the elastic modulus $E$, so $u$ must be in direct proportion to $\sigma / E$. In the formula (1), since $R$ is the only quantity with the dimension of length, the result is as follows:

$$
u \sim(\sigma / E) R
$$

Thus, according to Fig 1, it shows in the model that the comlete contact condition can be given through the dimensional argument:

$$
h / \lambda \approx \sigma_{0} / E
$$

However, according to the contact theory of Greenwood[1], the average pressure order which acts on the soft substrate contact area at the largest asperity is $(\Delta / r)^{1 / 2} E$, where $\Delta$ is the root-mean-square surface roughness amplitude and $r$ the average radius of curvature of the largest surface asperities. In the cosine corrugation surface of Fig 1, when $\Delta \approx r$, the local pressure in the contact area will be in the same order with the elastic modulus $E$, and fomula (2) \& (3) is thus obtained. In the formula (2) \& (3), the soft substrate deforms just enough to fill out at least some of the smaller sized surface cavities, while when $\Delta \geq r$, the smaller sized cavities can be fulfilled definitily. In order to verifying the correctness of the formula (3), under the condition of $\Delta \geq r$, the surface with the fine structure is constituted on the hard substrate to investigate whether the tiny leakage is occurred in the contact between hard and soft substrate.

\section{The Result and Analysis of Gaskets with Surface Fine Structure in Seal Experiment}

After the analysis of the contact and seal mechanics, two kinds of gaskets with the surface fine structure made from different materials and manufacturing processes are designed. The radius of the two gaskets is $10 \mathrm{~mm}$, and there is tunnel section in the center with $2.5 \mathrm{~mm}$ radius and $2 \mathrm{~mm}$ thickness. The gasket A is fabricated by IC processes, coated with $30 \mu \mathrm{m}$ thickness copper, using the chemical corrosion to build up the fine structure on the surface. The surface structure is designed as the concentric circles with reinforced tendons. The width of the concentric circles is $150 \mu \mathrm{m}$ and the gap between them is $500 \mu \mathrm{m}$. The finished product can be seen in Fig 2(a). In Fig 2(b), the test result by the surface profiler step tester shows that the processing quality of the chemical corrosion satisfies the design standard. 


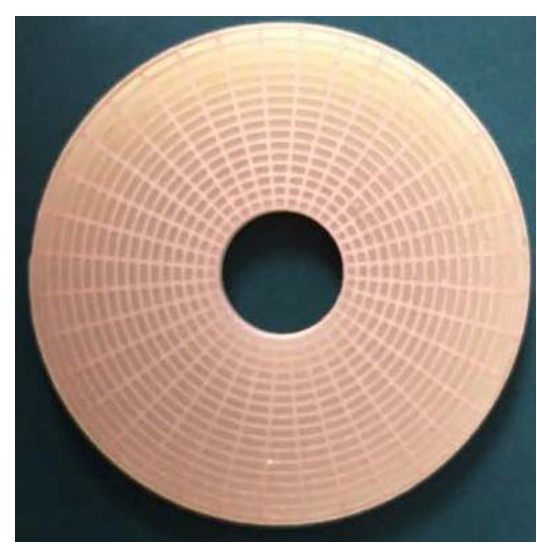

(a)

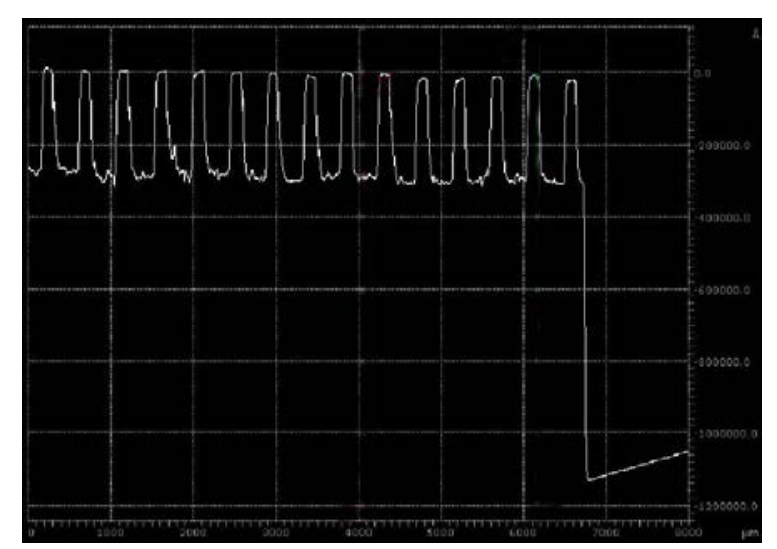

(b)

Fig. 2 (a) The finished product of the gasket A. (b) The test result of the surface profiler step tester

The aluminum alloy gasket $\mathrm{B}$ is fabricated by fine laser surface processing, with processing depth at $30 \mu \mathrm{m}$, and width at $30 \mu \mathrm{m}$ and the linear gap in the circles is $100 \mu \mathrm{m}$. The design configuration is the same as the gasket A. The finished product is shown in Fig 3(a). In Fig 3(b), the test result by the surface profiler step tester shows that the laser processing causes the hot melting salient zone on the edge; as a result, the grinding processing on the surface is needed in later phase.

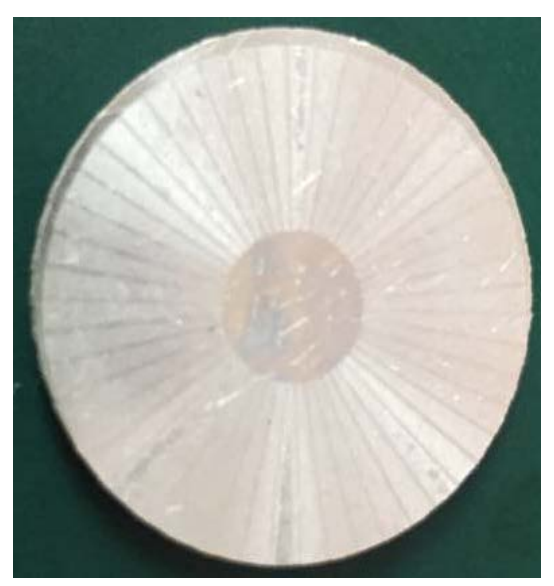

(a)

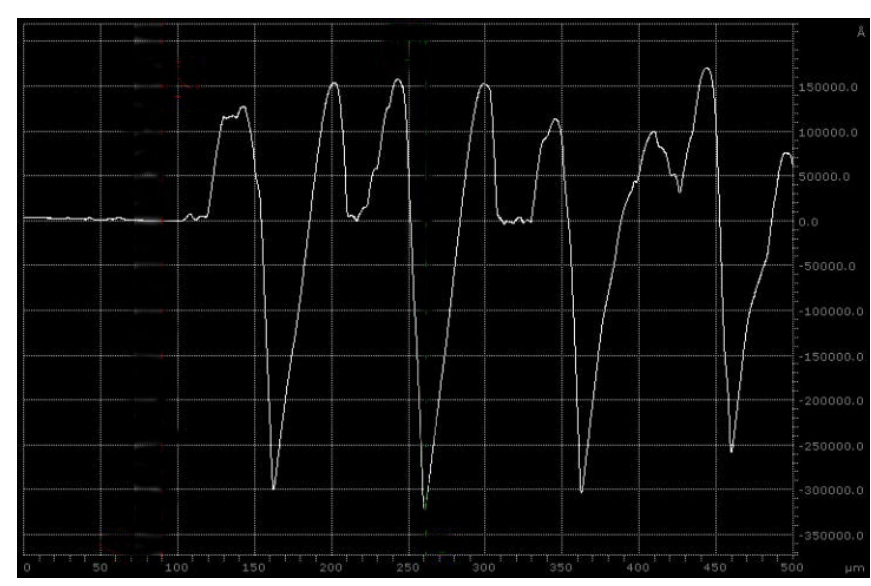

(b)

Fig. 2 (a) The finished product of the gasket B. (b) The test result of the surface profiler step tester

The seal experiment on the gasket $A$ and the grinded gasket $B$ is carried out. In the experiment, we used helium mass spectrum leak detector to test the seal performance of the gaskets who is in contact with the nylon ones, under $100 \mathrm{~kg}$ press force, and the test result with contract time order is displayed in Table 1.

Table 1 The Seal Performance of Different Gaskets

\begin{tabular}{|c|c|c|c|c|c|}
\hline \multirow{2}{*}{ No. } & \multirow{2}{*}{ Gasket Category } & \multirow{2}{*}{$\begin{array}{l}\text { Time } \\
(\min )\end{array}$} & \multirow{2}{*}{$\begin{array}{c}\text { Gas } \\
\text { Pressure }\end{array}$} & \multicolumn{2}{|c|}{ Helium Result $\left(\mathrm{Pa} \times m^{2} / s\right)$} \\
\hline & & & & Environment & Gasket leakage \\
\hline \multicolumn{6}{|c|}{ Smooth metal gasket } \\
\hline 1 & \multirow{3}{*}{$\begin{array}{l}\text { Smooth metal gasket } \\
+ \text { nylon substrate }\end{array}$} & 0 & $0.15 \mathrm{MPa}$ & $2 \mathrm{E}-8$ & 4E-7 slight leakage \\
\hline 2 & & 20 & $0.15 \mathrm{MPa}$ & $2 \mathrm{E}-8$ & 4E-6 slight leakage \\
\hline 3 & & 40 & $0.15 \mathrm{MPa}$ & $3 E-8$ & 8E-6 slight leakage \\
\hline \multicolumn{6}{|c|}{ Gasket A } \\
\hline 4 & \multirow{3}{*}{$\begin{array}{c}\text { Gasket A } \\
+ \text { nylon substrate }\end{array}$} & 0 & $0.1 \mathrm{MPa}$ & $2 \mathrm{E}-7$ & 4E-6 slight leakage \\
\hline 5 & & 20 & $0.1 \mathrm{MPa}$ & $2 \mathrm{E}-7$ & 2.5E-5 slight leakage \\
\hline 6 & & 40 & $0.1 \mathrm{Mpa}$ & $2 \mathrm{E}-7$ & 2.5E-5 slight leakage \\
\hline \multicolumn{6}{|c|}{ Gasket B } \\
\hline 7 & \multirow{3}{*}{$\begin{array}{c}\text { Gasket B } \\
+ \text { nylon substrate }\end{array}$} & 0 & $0.2 \mathrm{MPa}$ & 0E-9 & 0E-9 no leakage \\
\hline 8 & & 20 & $0.3 \mathrm{MPa}$ & 0E-9 & 0E-9 no leakage \\
\hline 9 & & 40 & $0.3 \mathrm{MPa}$ & 0E-9 & 0E-9 no leakage \\
\hline
\end{tabular}


As the Table 1 indicates, a good seal performance can be generated by the contact of the gasket $\mathrm{B}$ with nylon gasket. However, the gasket A displays the leakage even larger than the untreated smooth metal gasket. Considering this problem, a premise can be introduced for the verification of the contact theory in section 2 . Since the deformation of the nylon gasket is not sufficient enough to fit the bottom while in contact with the gasket $\mathrm{A}$, the gap between them may be generated, which may cause leakage.

In this case, Persson advanced the complete contact condition in the section 2 of this paper as shown in Fig 1 . When $h / \lambda \approx \sigma_{0} / E$, the deformation of the soft substrate can be sufficient enough to be in contact with the surface of the gasket everywhere. As for the gasket $\mathrm{A}$ whose press force is invariant, $\mathrm{h}=15 \mu \mathrm{m}, \lambda=500 \mu \mathrm{m}, \sigma_{0}=3.12 \mathrm{MPa}$ and $\Delta \geq r$, It can be indicated from the Formula (3) that the elastic modulus of the soft substrate can be in contact with the gasket everywhere when $E \leq 104 M P a$. In order to verify this theory, we carried out the further experiment with different soft substrates. And the results are displayed in the Table 2.

Table 2 The Seal Performance of Gasket A Contacting Different Substrates

\begin{tabular}{|c|c|c|c|c|c|}
\hline \multirow{2}{*}{ No. } & \multirow{2}{*}{ Gasket Category } & \multirow{2}{*}{$\begin{array}{l}\text { Time } \\
(\min )\end{array}$} & \multirow{2}{*}{$\begin{array}{c}\text { Gas } \\
\text { Pressure }\end{array}$} & \multicolumn{2}{|c|}{ Helium Result $\left(\mathrm{Pa} \cdot \mathrm{m}^{\mathrm{a}} / \mathrm{s}\right)$} \\
\hline & & & & Environment & Gasket leakage \\
\hline 1 & \multirow{4}{*}{$\begin{array}{l}\text { Gasket A + silica gel } \\
\qquad(\mathrm{E}=2.14 \mathrm{MPa})\end{array}$} & 1 & $0.1 \mathrm{MPa}$ & 3.7E-8 & $4.2 \mathrm{E}-8$ \\
\hline 2 & & 5 & $0.1 \mathrm{MPa}$ & $3.8 \mathrm{E}-8$ & $4.1 \mathrm{E}-8$ \\
\hline 3 & & 25 & $0.1 \mathrm{MPa}$ & $4.0 \mathrm{E}-8$ & $4.7 \mathrm{E}-8$ \\
\hline 4 & & 40 & $0.1 \mathrm{MPa}$ & $3.5 \mathrm{E}-8$ & $4.8 \mathrm{E}-8$ \\
\hline 5 & \multirow{3}{*}{$\begin{array}{l}\text { Gasket A + Teflon } \\
\quad(E=550 \mathrm{MPa})\end{array}$} & 1 & $0.1 \mathrm{MPa}$ & $3.4 \mathrm{E}-8$ & $5.2 \mathrm{E}-5$ \\
\hline 6 & & 4 & $0.1 \mathrm{MPa}$ & $3.4 \mathrm{E}-8$ & $5.8 \mathrm{E}-5$ \\
\hline 7 & & 20 & $0.1 \mathrm{MPa}$ & $3.8 \mathrm{E}-8$ & $2 \mathrm{E}-4$ \\
\hline 8 & \multirow{4}{*}{$\begin{array}{l}\text { Gasket A + nylon } \\
(\mathrm{E}=2830 \mathrm{MPa})\end{array}$} & 1 & $0.1 \mathrm{MPa}$ & $4.0 \mathrm{E}-8$ & $1.2 \mathrm{E}-7$ \\
\hline 9 & & 5 & $0.1 \mathrm{MPa}$ & $3.8 \mathrm{E}-8$ & $4.1 \mathrm{E}-7$ \\
\hline 10 & & 20 & $0.1 \mathrm{MPa}$ & $3.2 \mathrm{E}-8$ & $3.2 \mathrm{E}-7$ \\
\hline 11 & & 40 & $0.1 \mathrm{MPa}$ & 3.3E-8 & $3.4 \mathrm{E}-8$ \\
\hline 12 & \multirow{2}{*}{$\begin{array}{l}\text { Gasket A + polyurethane } \\
\qquad(\mathrm{E}=50 \mathrm{MPa})\end{array}$} & 1 & $0.1 \mathrm{MPa}$ & 5.3E-8 & 5.3E-8 \\
\hline 13 & & 40 & $0.1 \mathrm{MPa}$ & $4.8 \mathrm{E}-8$ & $4.8 \mathrm{E}-8$ \\
\hline 14 & \multirow{2}{*}{$\begin{array}{c}\text { Gasket } A+\text { rubber } \\
(E=6 \mathrm{MPa})\end{array}$} & 1 & $0.1 \mathrm{MPa}$ & 5.3E-8 & 5.3E-8 \\
\hline 15 & & 30 & $0.1 \mathrm{MPa}$ & $3.3 \mathrm{E}-8$ & $3.8 \mathrm{E}-8$ \\
\hline
\end{tabular}

It can be seen from the experiment result, sealing can be realized by the contact of the gasket $\mathrm{A}$ with the soft substrates like silica gel, polyurethane and rubber whose elastic modulus are $E \leq 104 M P a$, while the leakage occurred by the contact of the gasket A with the soft substrates made of Teflon and nylon whose elastic modulus is $E \geq 104 M P a$. According to data analysis in Table 2, we verified the complete contact condition in the Persson theory, that is, when $h / \lambda \approx \sigma_{0} / E$, the soft substrate can be deformed enough to be in contact with the surface of the gasket everywhere.

\section{Conclusions}

According to the analysis of the contact deformation between hard and soft substrates in Persson theory, in order to verify the complete contact condition, we designed the gaskets by processing the surface with fine structure under the condition that the tiny wave on the salient fulfills $\Delta \geq r$. The gasket A was fabricated by chemical corrosion processing; and the gasket $\mathrm{B}$ by fine laser surface processing, which both produced the fine structure in micrometer size. And we tested the quality of the gaskets with surface profiler step tester. The gasket B made of aluminum alloy by applying laser processing on the surface with the fine structure was grinded against the hot melting salient zone on the edge in gasket $\mathrm{B}$ to fulfill the processing standard.

After the seal performance experiment with helium mass spectrum leak detector, we conclude that the performance of the gasket B is superior over that of the gasket $\mathrm{A}$. And we put forward an assumption that the leakage of the gasket $\mathrm{A}$ is owing to the insufficient deformation in the soft substrate, and we conducted experiment to verify the complete contact condition. After the experiment, we find out that the result is identical with the soft substrate deform theory. And that 
when the elastic modulus of the soft substrate is $E \leq 104 M P a$, the gasket A can be sealed perfectly. At the same time, the experiment verified Persson's complete contact condition: under the condition that the tiny wave on the salient satisfies $\Delta \geq r$, if $h / \lambda \approx \sigma_{0} / E$, the soft substrate can be deformed enough to fulfill the wave everywhere on the hard surface. In summary, fabricating the micrometer size fine structure on the surface of the hard substrate can improve the seal performance in the contact of the hard with the soft. And it is not difficult to infer that if the fine structure on the surface of the hard substrate below micrometer size can be fabricated, it can improve the seal performance in the contact between the hard substrate.

\section{References}

[1]. Persson B.N.J. Theory of Rubber Friction in Contact Mechanics. Journal of Chemical Physics. Vol. 115 (2001) p. 3840.

[2]. J. A. Greenwood. in Fundamentals of Friction, Macroscopic, and Micro-scopic Processes. Kluwer, Dor-drecht, 1992.

[3]. Persson B.N.J. Contact mechanics for randomly rough surface. Surface Science Report. Vol. 61 (2006) p. 201-227. 